\title{
Multiple Angiodysplasia in the Stomach
}

\author{
Jong Kyu Park
}

Department of Internal Medicine, Gangneung Asan Hospital, University of Ulsan College of Medicine, Gangneung, Korea

Question: A 62-year-old female presented to the emergency department with dizziness that commenced 5 hours after the development of melena and coffee ground vomitus. Her blood pressure was 140/70 mm Hg and her heart rate 98 beats/minute. The hemoglobin level and hematocrit were abnormally low at $4.8 \mathrm{~g} / \mathrm{dL}$ and $18.7 \%$, respectively. She had a 5-year history of recurrent spontaneous epistaxis treated in the ear, nose, and throat department. Her mother had also experienced recurrent episodes of epistaxis. Physical examination revealed multiple tongue telangiectasias. Esophagogastroduodenoscopy revealed multiple angiodysplasias (but no current bleed- ing) on the antrum, body, and fundus (Fig. 1). Epistaxis developed during endoscopy. Abdominal, computed tomographic angiography revealed hepatic artery hypertrophy and early enhancement of the portal and hepatic veins, suggestive of arterio-portal and arterio-venous shunts (Fig. 2). No mucosal abnormality was found on colonoscopy. A red blood cell bleeding scan was negative in terms of gastrointestinal bleeding. Computed tomography revealed no pulmonary or cerebral vascular malformation.

What is the most likely diagnosis?
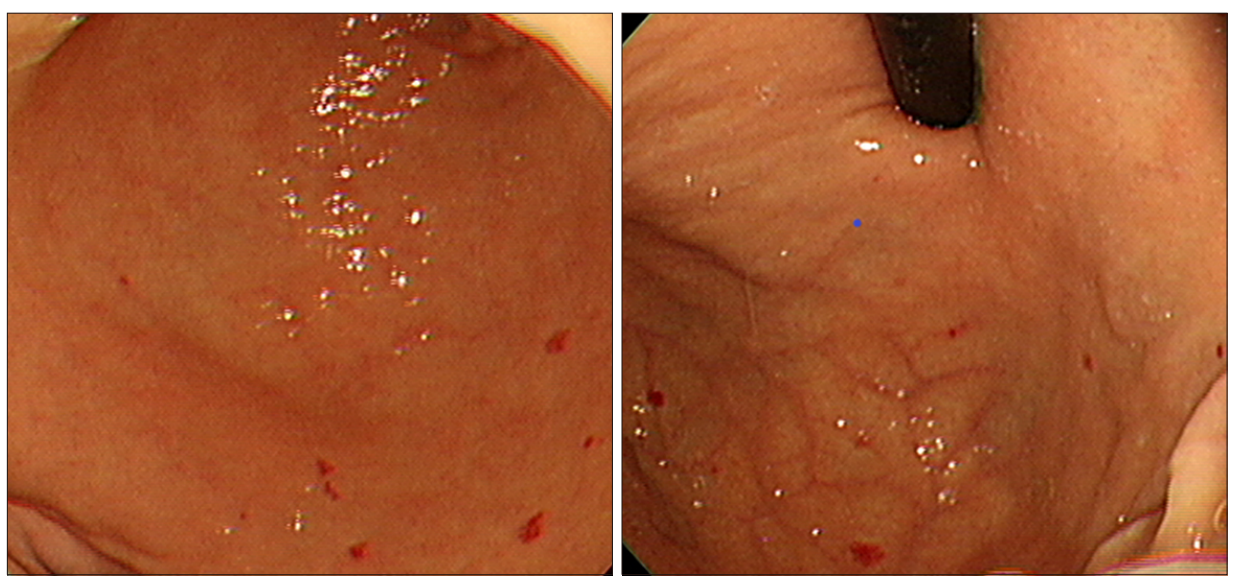

Fig. 1. Endoscopy reveals multiple reddish vascular tufts on the antrum and fundus.

Received: October 16, 2018 Revised: November 20, 2018 Accepted: November 21, 2018

Corresponding author: Jong Kyu Park

Department of Internal Medicine, Gangneung Asan Hospital, University of Ulsan College of Medicine, 38 Bangdong-gil, Sacheon-myeon, Gangneung 25440, Korea Tel: +82-33-610-3949, Fax: +82-33-641-8130, E-mail: sajahoooo@naver.com

Copyright $\odot 2019$ Korean College of Helicobacter and Upper Gastrointestinal Research

@ The Korean Journal of Helicobacter and Upper Gastrointestinal Research is an Open-Access Journal. All articles are distributed under the terms of the Creative Commons Attribution Non-Commercial License (http://creativecommons.org/licenses/by-nc/4.0) which permits unrestricted non-commercial use, distribution, and reproduction in any medium, provided the original work is properly cited. 

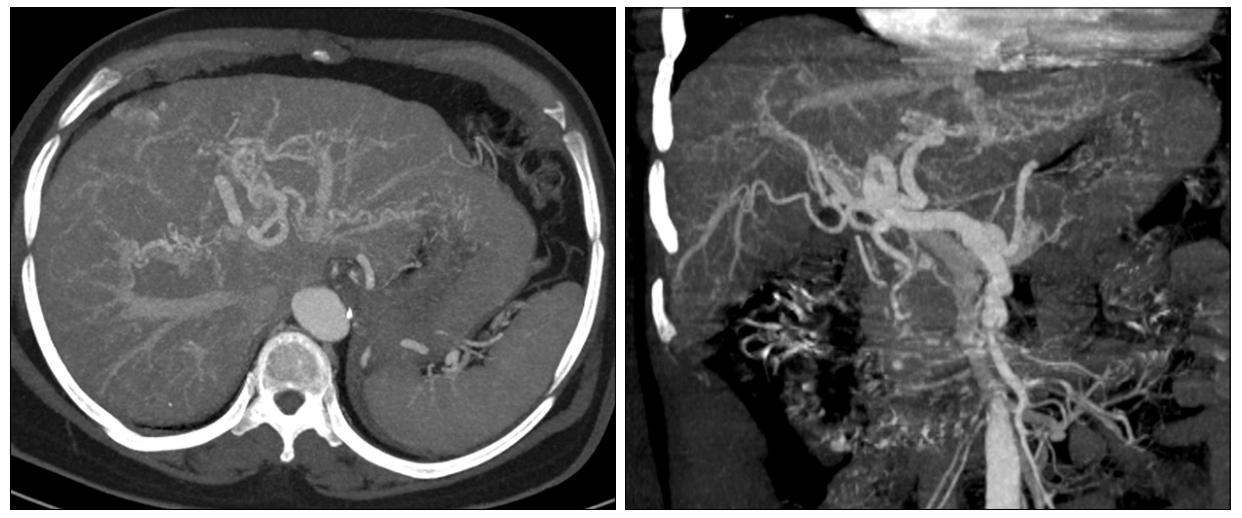

Fig. 2. Abdominal, computed tomographic angiography reveals tortuous, hepatic artery hypertrophy; early enhancement of the portal and hepatic veins; and heterogeneous enhancement of the liver parenchyma.

Answer: On the basis of the findings described above, the patient was clinically diagnosed with hereditary hemorrhagic telangiectasia (HHT) (also termed Osler-WeberRendu syndrome) based on the four Curaçao clinical criteria. These are (1) spontaneous recurrent epistaxis; (2) multiple mucocutaneous telangiectasias on the lips, oral cavity, fingers, and nose; (3) visceral lesions including gastrointestinal telangiectasias; and pulmonary, hepatic, cerebral, and spinal arteriovenous malformations; and (4) an affected first-degree relative. "Definite HHT" is defined when three criteria are met, "suspected HHT" when two criteria are met, and "unlikely HHT" when one criterion is met. Our patient met all four criteria.

Gastrointestinal bleeding in patients with HHT usually commences in the fourth or fifth decade of life but only in $13 \sim 33 \%$ of patients. $^{2}$ Telangiectasias are more common in the stomach and duodenum than the colon. In most cases, no treatment is required. A bleeding gastrointestinal lesion may be amenable to endoscopic therapy. Embolization and surgery are of limited utility because the disease is recurrent, but may be useful to control bleeding in an emergency. In Korea, gastric bleeding has been treated via argon plasma coagulation and band ligation, and ileocolic bleeding via embolization. ${ }^{3-5}$ If a patient presenting with gastrointestinal bleeding reports recurrent episodes of spontaneous epistaxis, and multiple angiodysplasias are evident on endoscopy, family history-taking may reveal recurrent bleeding episodes, triggering radiological evaluation on suspicion of HHT.

\section{CONFLICT OF INTEREST}

No potential conflict of interest relevant to this article was reported.

\section{ORCID}

Jong Kyu Park @ilttps://orcid.org/0000-0002-5474-6794

\section{REFERENCES}

1. Begbie ME, Wallace GM, Shovlin CL. Hereditary haemorrhagic telangiectasia (Osler-Weber-Rendu syndrome): a view from the 21st century. Postgrad Med J 2003;79:18-24.

2. Kjeldsen $A D$, Kjeldsen J. Gastrointestinal bleeding in patients with hereditary hemorrhagic telangiectasia. Am J Gastroenterol 2000;95:415-418.

3. Hwang IS, Cho H, Kim MY, et al. A case of endoscopic band ligation therapy for gastric bleeding in patient with RenduOsler-Weber disease. Korean J Gastrointest Endosc 2001;23: 470-473.

4. Jung MK, Lee JY, Lee HC, et al. A case of hereditary hemorrhagic telangiectasia treated by argon plasma coagulation. Korean J Gastrointest Endosc 2008;36:14-17.

5. Kim YJ, Park AW, Sim JI, Ryeom HK. Transcatheter embolization therapy of the gastrointestinal hemorrhage. J Korean Radiol Soc 1994;30:823-828. 